\title{
Can Technology Be Leveraged for Bridging the Rural-Urban Divide?
}

\author{
Anuragini Shirish $^{1(\mathbb{})}(\mathbb{D})$, Shirish C. Srivastava ${ }^{2}(\mathbb{D})$ \\ and G. Shainesh ${ }^{3}$ (D) \\ ${ }^{1}$ LITEM, Univ Evry, IMT-BS, Université Paris-Saclay, 91025 Evry, France \\ anuragini.shirish@imt-bs.eu \\ ${ }^{2}$ HEC Paris, Paris, France \\ ${ }^{3}$ IIM Bangalore, Bengaluru, India
}

\begin{abstract}
Inequalities exist and persist in society in different forms and are often areas of prime concern for governments and policy makers around the globe. One such inequality that plagues societies is the rural-urban divide. Several social entrepreneurs are attempting to leverage technology to bridge this divide. In our research-in-progress paper, we describe the case of an Indian company, which is leveraging technology to create knowledge-based jobs for the rural Indian population. The approach adopted by the company in initiating and sustaining such an effort was an inside-out approach in contrast to the usual approach of focusing only on the internal resources within the company. Specifically, our research aims at abstracting the process mechanisms that enabled such an initiative. The unearthed mechanisms would inform future research on the modalities for orchestrating such an initiative. The findings would also help practitioners, especially social entrepreneurs, to think of innovative business models that would create value not only for the company but also for society as a whole. The delineated learnings would also help enthused social entrepreneurs to transplant such initiatives to other regions of the world.
\end{abstract}

Keywords: Rural-urban divide $\cdot$ Reverse innovation $\cdot$ ICT for development • Business model innovation

\section{Introduction}

Global wealth has risen to a new high of 361 trillion US Dollars in 2019 but unfortunately, only a very small group at the top has captured most of the increase. The top $1 \%$ of the world's population accounts for nearly $45 \%$ of the total wealth, while the bottom $50 \%$ owns only $1 \%$ of the total wealth [5]. Such stark inequalities exist and persist in the society in different forms (e.g. regional, racial and gender) and are often areas of prime concern for governments and policy makers around the globe. For example, the recent yellow vests protests (Gilets Jaunes) in France or the farmer protests in India are attributable to the growing discontentment due to the rural-urban divide [2, 3]. While governments are primarily responsible for reducing these inequalities are primarily viewed as governmental tasks, several grassroots social entrepreneurs, especially in developing countries are implementing innovative local solutions to bridge these gaps 
[11]. Such innovative bridging solutions often involve extensive use of Information and Communication Technologies (ICTs) [16]. However, the modalities and mechanisms through which these solutions are orchestrated are highly contextualized and need to be examined $[1,9]$. Deep theoretical abstractions emerging from an understanding of these inequality-bridging mechanisms can greatly benefit other inequality-ridden contexts and regions through the process of reverse innovation [7].

Grounding our work in social resource-based view (SRBV) and the literature on reverse innovation and information systems, we examine an impactful social entrepreneurship initiative in a developing country context, with a view to transplant the learnings to the required pockets in other developing and developed economies [6, $7,12,14,17]$. We believe that such an effort will be useful in developing impactful theories for reducing the inequalities within countries. In our study, we focus on bridging the urban-rural divide, as it is one of the areas that the governments of most countries around the world are concerned. In specific, we focus on a grassroots social entrepreneurship initiative (rather than focusing on government-sponsored initiatives) aimed at reducing the rural-urban inequalities. Our study is set in the Indian context, which serves as a fertile ground for many social entrepreneurship initiatives. As aforementioned, our focus will be on how the learnings/theoretical abstractions from this initiative could be translated to benefit other parts of the world.

The two research questions that we intend to examine in our study are:-

1. How are social entrepreneurship initiatives in developing countries conceptualized and executed to bridge the rural-urban divide?

2. What are the key enablers that facilitate delivery of such ICT-enabled bridging solutions in the context of developing countries?

\section{Research Context}

To better appreciate the research setting and the problem proposed to be examined in our study, it would be necessary to understand the rural-urban divide in the Indian context. According to the 2011 Census Report, $83.3 \%$ of India's population lives in rural areas. However, most economic and service benefits are accrued by the urban centers. For example, in the health care sector nearly $75 \%$ of medical dispensaries, $60 \%$ of the hospitals and $80 \%$ of doctors are located in urban areas. Similarly, there are limited regular employment opportunities in rural areas leading to a large-scale migration to the urban centers creating undue pressure on the limited resources in Indian cities. According to the 2017 National Economic Survey, 8 to 9 million people migrate for work opportunities within India annually, which is severely affecting the quality of life in urban centers. Some studies have projected that by 2050, more than half of India will be living in urban areas, which will further accentuate the issues related to the quality of life in urban centers. 


\section{Background Literature}

We ground our research in the social resource-based view (SRBV). So far literature has mainly used the resource based view (RBV) or natural resource based view (NRBV) approach to understand how companies can achieve economic performance or environmental performance as a competitive advantage by using their own internal resources and by deploying internal capabilities [8]. Recent work by Tate and Bals [18] uses social entrepreneurship literature and extends the RBV and NRBV logic, which is primarily based on instrumental parameters of economic performance, to that of social performance. In summary, SRBV integrates social capabilities with Triple Bottom Line (TBL) sustainability outcomes related to social, economic and environmental impacts.

Tate and Bals [18], through inductive case studies, conceptualized several social strategic capabilities, social driving forces and key resources that contribute to shared TBL value creation. An SRBV allows us to study social capabilities, allows us to examine complex stakeholders embedded in different domains such as those with economic, environmental, and/or social stakes. The theory also offers the possibility to link social capabilities and shared TBL value creation. Thus, SRBV allows us to study the social capabilities of grassroot social entrepreneurs acting as the micro-foundations for bringing about societal change. However, the propositions of SRBV have not yet been tested empirically, and the process view on how the resource and capabilities integration takes place, needs further examination. Because embedded innovation and social innovations are influenced by ambiguities and uncertainties in the external environment, exploring TBL value creation by social entrepreneurs is highly complex. Research that demonstrates how social capabilities are orchestrated by hybrid organizations such as grassroots social entrepreneurs using SRBV for alleviating social issues at the Bottom of the Pyramid (BoP) will be a valuable contribution to academic literature as well as practice $[8,18]$.

We believe that actions taken at various stages of an entrepreneurship project in general and a resource-constrained social entrepreneurship project in particular are based on the ability of the entrepreneur to leverage the internal resources within the company and garner resources from outside the company (based on the emergent need) as shown by SRBV. This resource orchestration exercise is a dynamic one that continuously evolves as the project unfolds. Our aim is to understand this evolutionary process with a view to perhaps replicate it in other contexts.

\section{Method}

This research aims at theory building by adopting a social resource-based view (SBRV) perspective. We intend to use a qualitative case-based methodology and a process view to analyze data from an Indian company (VillageTechServ ${ }^{1}$ ) (VTS) to understand the social resource-based actions that the company undertook to fulfil their objective of creating jobs for the rural Indian population. We will also examine how these patterns

\footnotetext{
${ }^{1}$ Name camouflaged - VillageTechServ (VTS for short).
} 
evolve over time [see 4, 13, 15]. Consistent with the case study approach, we will provide an overview of some of the streams of research that will contribute to our theory building, namely, literature on social resource-based view and the role of ICT for bridging societal inequalities. Finally, we intend to situate each of our findings within the literature to contextualize the emergent theoretical concepts before arriving at our theoretical and practical implications.

Our study utilizes a mix of primary and secondary data to analyze the research problem. We have already conducted 42 interviews and have attended several presentations given by the senior management team of the VTS. Many of the key respondents were interviewed multiple times to clarify new facts as they emerged during the data collection process. We took detailed notes during all interviews. We also had email exchanges with officials for an in-depth understanding of the underlying processes, mechanisms, and interactions associated with their implementation process.

We also visited the VTS work centers at different locations in India and took detailed observational notes during the site visits, which will form part of the data for our analysis. For secondary data, we went through the organizations' activity reports, websites, published articles, internal reports, and video clips. We are using a process view to analyze the data, aimed at unearthing the patterns of their resource-based actions to understand how their implementation unfolded $[4,10]$.

\section{Preliminary Findings and Expected Implications}

India, traditionally has been one of the world's major IT-services provider hub. However, these IT service centers are primarily located in big cities such as Bangalore, New Delhi, Hyderabad and Chennai. VTS was initiated in 2008 on the premise of creating knowledge-based jobs for rural Indian population. The founder of VTS had the idea of sourcing some of the knowledge work from the villages with a view to provide the rural population with steady incomes through meaningful employment. The mission of VTS is a social one-to enskill, employ, empower and engage the rural youth. Their objective is to provide sustainable employment to 100,000 rural youth by opening business process outsourcing (BPO) centers in each of the 500 rural districts of India. They particularly want to create shared value in TBL, i.e. on the economic front, the social front and the environmental front. They are a hybrid organization that focuses on integrating their resources and capabilities for creating shared values through impact souring, training, rural employment, family saving, social engagement and conserving environmental ecosystems of the local rural districts. As of 2019, they have 16 Business Process Outsourcing (BPO) rural centers in north, south, east, west and central India. $65 \%$ of their clients are from the telecom sector and the remainder $35 \%$ comprise diverse sectors related to logistics and retail. VTS is perhaps the world's largest and relatively oldest (10 years) rural IT services company offering sustainable direct and indirect social value to its stakeholders since its inception.

Although setting a village IT service center may appear to be a straightforward process, it is not a simple exercise. Many of the taken for granted resources in the urban centers are unavailable in rural areas. The two primary contextual constraints, which made this venture extremely difficult, were (1) the rural areas did not have efficient 
Internet connectivity and regular power supply, and (2) there was an absence of sufficiently trained employable workers for knowledge based IT service jobs in rural areas. To tackle these challenges, VTS took upon itself to arrange for the required infrastructure as well as to develop the required manpower skills for making the IT-enabled service centers operational. Apart from socially driven motivations, the founders of VTS were confident that the trained employees would be permanent assets for the company because the jobs (or rather opportunities) had moved to their villages so there would be less attrition. Job turnover or attrition is one of the major challenges faced by the IT services sector in India (with attrition rates in some cities touching a high of $25 \%$ ). In addition to having near zero attrition rates, the cost of wages are also much lesser in rural centers simply because the living costs in rural areas are significantly lesser than in cities.

Some measurable social value impacts created by VTS include, providing direct employment for 5280 rural youth (in 2018). Out of these $90 \%$ were internally trained after employment. $40 \%$ of employment was provided for the female youth. $5 \%$ of these beneficiary are persons with disabilities. The average family income increased by $65 \%$ from the current income level due to jobs at VTS. At the societal level the rate of migration from rural area to cities in search of jobs have reduced to $55 \%$ in the villages where the initiative has been undertaken. A positive spinoff that the research team discovered in its initial interviews is that some of the villages that were initially selected by VTS for starting IT service centers now have permanent schools and the income levels in these villages have risen, leading to better quality of life for many people living in those villages. The journey of VTS has been one of trial and error. In fact, following the philosophy of reverse innovation, VTS has set up a centre in San Jose, California to create employment opportunities to the underprivileged and disadvantaged youth.

Thus far, we see empirical evidence for propositions of the emergent theory on SRBV. VTS is an example of how TBL values are generated by grassroots social entrepreneurs who know how to use their social capabilities such as social innovative model, mission driven approach and stakeholder management for bridging opportunity divide in the society. Social values that are generated by this initiative include providing access to food, access to decent livelihood, access to education, access to secure income, access to meaningful employment, access to equality and access to involve in community engagement. In our research, we seek to unravel these theoretical mechanisms which can perhaps be replicated by other aspiring social entrepreneurs. This allows us to understand how social entrepreneurship initiatives in developing countries can be conceptualized and executed to bridge the rural-urban divide. Our study hopes to unearth specific key enablers for facilitating the delivery of ICT-enabled bridging solutions in the context of developing countries.

\section{References}

1. Bamberger, P.: Beyond contextualization: using context theories to narrow the macro-micro gap in management research. Acad. Manage. J. 51(5), 839-846 (2008). https://doi.org/10. 5465/amj.2008.34789630 
2. Bera, S.: Farmers' protests brings urban rural divide to the fore. https://www.livemint.com/ Politics/HS3QyD9dGUfCjXfThTZUHL/Farmers-protests-brings-urban-rural-divide-to-thefore.html. Accessed 28 Oct 2019

3. Bruneau, I., Mischi, N., Renahy, J.: Rural France in Revolt. https://jacobinmag.com/2019/ 03/gilets-jaunes-rural-dispossession-macron. Accessed 28 Oct 2019

4. Chakraborty, S., Sarker, S., Sarker, S.: An exploration into the process requirements elicitation: a grounded approach. J. Assoc. Inf. Syst. 11(4), 212-249 (2010). https://doi.org/ 10.17705/1jais.00225

5. Suisse, C.: Global Wealth Report 2019, Credit Suisse Research Institute. https://www.creditsuisse.com/about-us/en/reports-research/global-wealth-report.html. Accessed 28 Oct 2019

6. Govindarajan, V., Trimble, C.: Reverse Innovation: Create Far From Home, Win Everywhere. Harvard Business Review Press, Cambridge (2012). https://doi.org/10.1108/ sajgbr-03-2013-0023

7. Govindarajan, V., Ramamurti, R.: Reverse innovation, emerging markets, and global strategy. Global Strategy J. 1(3-4), 191-205 (2011). https://doi.org/10.1002/gsj.23

8. Hart, S.L., Dowell, G.: A natural-resource-based view of the firm: fifteen years after. J. Manage. 37(5), 1464-1479 (2010). https://doi.org/10.1177/0149206310390219

9. Johns, G.: The essential impact of context on organizational behavior. Acad. Manage. Rev. 31(2), 386-408 (2006). https://doi.org/10.5465/amr.2006.20208687

10. Lyytinen, K., Newman, M.: Explaining information system change: a punctuated sociotechnical change model. Eur. J. Inf. Syst. 17(6), 589-613 (2008). https://doi.org/10.1057/ ejis. 2008.50

11. Mair, J., Marti, I., Canly, K.: Institutional voids as spaces of opportunity. Eur. Bus. Forum 31, 34-39 (2007). https://doi.org/10.1016/j.jbusvent.2008.04.006

12. Saebi, T., Foss, N.J., Linder, S.: Social entrepreneurship research: past achievements and future promises. J. Manag. 45(1), 70-95 (2019). https://doi.org/10.1177/0149206318793196

13. Sarker, S., Sarker, S., Sahaym, A., Bjorn-Andersen, N.: Exploring value cocreation in relationships between an ERP vendor and its partners: a revelatory case study. MIS Q. 36(1), 317-338 (2012). https://doi.org/10.2307/41410419

14. Sen, A.K.: Development as capability expansion. J. Dev. Plan. 19, 41-58 (1989). https://doi. org/10.1007/978-1-349-21136-4_3

15. Silva, L., Hirschheim, R.: Fighting against windmills: strategic information systems and organizational deep structures. MIS Q. 31(2), 327-354 (2007). https://doi.org/10.2307/ 25148794

16. Srivastava, S.C., Mithas, S., Jha, B.: What is your global innovation strategy? IT Prof. 15(6), 2-6 (2013). https://doi.org/10.1109/mitp.2013.102

17. Srivastava, S.C., Shainesh, G.: Bridging the service divide through digitally enabled service innovations: evidence from Indian healthcare service providers. MIS Q. 39(1), 245-267 (2015). https://doi.org/10.25300/misq/2015/39.1.11

18. Tate, W.L., Bals, L.: Achieving shared triple bottom line (TBL) value creation: toward a social resource-based view (SRBV) of the firm. J. Bus. Ethics 152(3), 803-826 (2016). https://doi.org/10.1007/s10551-016-3344-y 